\title{
Understanding How the 4.0 Guaranteed Plan Works
}

\section{Dr. Mary R. Anderson-Rowland, Arizona State University}

Mary Anderson-Rowland, Arizona State University MARY R.ANDERSON-ROWLAND is the PI of an NSF STEP grant to work with five non-metropolitan community colleges to produce more engineers, especially female and underrepresented minority engineers. She also directs an Academic Success and Professional Development program, with an emphasis on transfer students. An Associate Professor in Computing, Informatics, and Systems Design Engineering, she was the Associate Dean of Student Affairs in the Ira A. Fulton Schools of Engineering at ASU from 1993-2004. Anderson-Rowland was named a top 5\% teacher in the Fulton Schools of Engineering for 2009-2010. She received WEPAN's Betty Vetter Research Award 2015, the WEPAN President's Award 2014, WEPAN's Engineering Educator Award 2009, ASEE Minorities Award 2006, the SHPE Educator of the Year 2005, and the National Engineering Award in 2003, the highest honor given by AAES. In 2002 she was named the Distinguished Engineering Educator by the Society of Women Engineers. She has over 190 publications primarily in the areas of recruitment and retention of women and underrepresented minority engineering and computer science students. Her awards are based on her mentoring of students, especially women and underrepresented minority students, and her research in the areas of recruitment and retention. A SWE Fellow and ASEE Fellow, she is a frequent speaker on career opportunities and diversity in engineering. 


\title{
Understanding How the 4.0 Guaranteed Plan Works
}

\begin{abstract}
For many students, a good college experience requires more than can be found in just the classroom. Some student groups such as female, underrepresented minority, transfer students, or those with unmet financial need can do very well in a college or university with just a little encouragement and help. In fact, the National Science Foundation has been supporting scholarship programs such as S-STEM for just such students with unmet financial need. The scholarships allow the students to work less or not at all, and to put more of their energy into academics. At Arizona State University, the author has led such scholarship programs with an Academic Success and Professional Development classes for nearly 15 years. During this time she has continually done research on the best way to support and encourage students to do well academically, to graduate, and to go right on to graduate school. This research has used grounded theory and Social Cognitive Career Theory to understand how best to recruit and retain students.

Beginning with seminars, over the years, the author developed a successful two-credit Academic Success and Professional Development class that is required of NSF scholarship recipients as a support to help them continue to do well academically. This class is also open to non-scholarship students, who are also upper division engineering and computer science students. In the spring of 2005 the "Guaranteed 4.0 Plan" by Donna O. Johnson Mackey was included as part of the course with immediate results. The 4.0 Plan training that the students receive, the 4.0 Plan class assignments, and the results of a survey given to the academic success students on the 4.0 Plan are described. The goal of this study is to understand how to better present the Guaranteed 4.0 learning system to assist students academically.
\end{abstract}

\section{Introduction}

Donna O. Johnson Mackey, an engineer with a passion for seeing engineering students succeed, has given workshops on her "Guaranteed 4.0 Plan" learning system for years. The 4.0 Plan was guaranteed in that if a student had been trained by Johnson, followed the plan completely, and did not receive straight A's at the end of the semester, she would personally give the student $\$ 100$. She has not had to pay out yet. In 2004 she wrote an impressive book of the same name. ${ }^{1}$ Having taught an Academic Success and Professional Development classes (currently sponsored by NSF S-STEM grant \#1060226 and NSF Motivated Engineering Transfer Students STEP grant $\# 0856834)$ ) for several years, the author learned that when semester evaluations asked students if the class had helped their academics, most said, "No." Now with Ms. Johnson's "learning system" carefully explained in a text, the students had a guide and the answer changed to "Yes."

A focus of the academic success class is upper division engineering and computer science female, underrepresented minority, and transfer students, including many first generation students and most from community colleges (CCs). About $60 \%$ of the NSF scholarships since 2002 have gone to these focused groups and S-STEM and STEP scholarship students are required to take a two-semester credit Academic Success and Professional Development class 
each semester they have the scholarship. Upper division engineering and computer science students (henceforth called ENGR students) without scholarships are also welcome to take the course. The course includes topics such as resumes, interviews, how to work a career fair, portfolios, detailed time management, career planning, research, internships, graduate school, a graduate student panel, and engineering speakers from industry.

Upon adding the Johnson "learning to learn" material in the Academic Success class, there were immediate results. Students who were already earning a 4.0 GPA could now do so with less work using the 4.0 Plan. One student said, "At last, after seeing my grades go down each semester, I have a plan to bring them back up." One student with less than a 2.5 GPA, earned a 3.9+ GPA the first semester he tried the 4.0 Plan. The Plan obviously helps the students as they are encouraged to go for a 4.0, or at least a 3.5 GPA which is required of some of the 4+1 Programs available in engineering and computer science for students to be able to earn a Master's Degree in one year after their Bachelor's degree.

Which parts of the Plan are the most important to the students, in general, was not known. In Fall 2015, a survey on the components associated with the 4.0 Plan was given to a class of 62 students with 59 students $(95.2 \%)$ responding. The results of this survey are given and analyzed. These results give insight into how the 4.0 Plan is perceived by the students and can be used in future instruction of the 4.0 Plan. The goal of all this is to help the ENGR student understand that there are things to learn about learning and methods that can be used to enhance learning.

For more information on the setting of the Academic Success and Professional Development class see previous publications. ${ }^{2,3,4,5,6}$

\section{Background}

At the end of each semester, the students in the Academic Success and Professional Development class are asked several questions in order to evaluate the effectiveness of the course. They are also asked some questions about the 4.0 Plan. They are asked to estimate what percentage of the Plan they actually use and are also to estimate what their GPA will be that semester. Although students are quite good at estimating their GPA, attempts in the past to see a correlation between the estimated percent usage of the 4.0 Plan and the student's GPA have failed. Some students with high GPAs claim to not use the 4.0 Plan at all, while students with a much lower GPA will estimate that they use $90-100 \%$ of the 4.0 Plan. Problems with trying to measure the effect of the 4.0 Plan include the fact that students are not very good at estimating what percent of the 4.0 Plan they use. Two students can estimate that they use the Plan $90 \%$ of the time and one student may have a 4.0 and the other less than a 2.0. At the same time some students will say they do not use it at all, but have a 4.0 GPA. Undoubtedly some of their study habits are similar to the 4.0 Plan.

A simple linear regression was fitted to the data with a sample of 18 freshmen students, with an $\mathrm{R}$-squared of $32.2 \%$. A better fit was obtained by including their high school ABOR GPA (Rsquared $=.487) .{ }^{7}$ A study was conducted which compared the first semester university GPA of upper division transfer students in the Academic Success class with the 4.0 Plan with new transfer students not in the class and who did not have the $4.0 \mathrm{Plan}^{8}{ }^{8}$ The study showed the 
average university GPA drop of 19 new community college transfers in the success class to be .112, which was not statistically significant. The 183 new transfer students not in the class had a significant average .4 grade drop. The 4.0 Plan is assumed to be the main difference factor.

Students who take the Academic Success and Professional Development class without scholarships usually do so because the class was recommended to them by a friend who had taken the class and found it helpful. Although this class is not set up as a remedial course, some students enroll as the result of an academic advisor relating that the class helps students raise their GPA. As an example, recently a transfer student in his second semester, who had taken the Academic Success and Professional Development class the last semester, ran into a friend he had not seen since they were at the same CC over a semester ago. In exchanging information, the Academic Success student realized that he had earned a 3.4 GPA last fall, while his friend had a GPA around 2.5 at the end of his first semester. The next day, the two young men were in the Transfer Center inquiring how the friend could get a late add to the Success class and the next day the friend was in the class.

It should be no surprise that there can be dramatic results with the Guaranteed 4.0 learning system. It is based on research. ${ }^{1}$ The primary research basis for the 4.0 Plan is that continued repetition puts information in the brain as learned material. To really learn an item, it must be repeated within 1 second, 1 hour, 1 day, and 1 week. Students who have gone over and over information will have learned it and will not need to "cram" the night before an exam to remember material. Bullet Point Reading (BPR), the basis of the 4.0 Plan, requires that students read over material 1-7 days before they hear the lecture on the material. When students read material ahead they are looking to extract the main ideas from the material, to translate that idea into 3-5 of their own words and to write those words next to a bullet point. In going through the material, at the end of each section, the bullet points are reviewed. Actually the student goes over the material several times in the BPR, then again during the lecture with listening and taking notes, and then again in doing Bullet Point Notes (doing bullet point reading with the lecture notes). The 4.0 learning system includes the following list of topics:

- Bullet Point Reading (BPR): reading material 1-7 days before class

- Going to class; taking good notes

- Bullet Point Notes (BPR): condensing notes right after class

- Start homework as soon as it is assigned

- If stuck in homework after 20 minutes, go on to something else

- Bullet Point Concepts: go over graded homework and exams to understand why you got it right, as well as wrong

- Professor Office Hours (POH): get to know each professor, visit at least once a week, $1 / 2$ hour appoint scheduled for each week

- Detailed Time Management Schedule

- Get 8 hours of sleep every night

- Be in a study group for each class

- Become involved in student organizations

- Know how to catch up without falling behind 
Related research shows that if the brain is already somewhat familiar with material, it behaves much more like a brain easily going over learned material than it does working hard to comprehend new material. In a scientific independent test, it was shown that people with only a very short introduction to bullet point reading, outperformed people in remembering material using the bullet point reading method rather than highlighting or just reading the material. Each new student to the class is given an hour presentation with a handout on the 4.0 Plan. All students must do several assignments in reference to the 4.0 Plan. Each semester the students need to make a new Detailed Management Plan for their new schedule of classes. The students are encouraged to keep their schedule dynamic, not cast in concrete. It is very difficult to estimate accurately how much time will be needed for each course in order to learn the material. If schedule changes need to be made, the students are encouraged to make the changes.

Academic Success students sometime complain that they are "forced" to do the Guaranteed 4.0 Leaning System and not given a choice to do another plan. They are told that if they can find another learning system that works, can be applied to ENGR, and which is guaranteed, it would be considered as an option. There are additional helps around such as how to take exams and memorizing techniques. This author is not aware of a better learning system than the 4.0 Plan.

\section{The Survey Setting}

The 59 students in the fall 2015 semester Academic Success and Professional Development class completed a survey on the 4.0 Plan. The students ranged in age from 18 to 30 . The students were all ENGR majors and most of the students were upper division status, with a few sophomores and some graduate students. About half of the students were transfer students. Fifteen of the students were in their first semester with the 4.0 Plan. The mix of the students by gender and ethnicity is as shown in Table I. The number of scholarship students in each category is given in parentheses. Thirty-six or $58.1 \%$ of the students who took the survey had an NSF scholarship.

Table I. Gender and Ethnicity of 59 Students Who Took the Survey

\begin{tabular}{|l|l|l|l|l|}
\hline Gender/Ethnicity & Minority & Non-Minority & Total & Percentage \\
\hline Female & $3(3)^{*}$ & $6(5)$ & $9(8)$ & $15.3 \%$ \\
\hline Male & $16(10)$ & $34(18)$ & $50(28)$ & $84.7 \%$ \\
\hline Total & $19(13)$ & $40(23)$ & $59(36)$ & $100 \%$ \\
\hline Percentage & $32.2 \%$ & $67.8 \%$ & $100 \%$ & \\
\hline
\end{tabular}

*The numbers in parentheses are the number of scholarship students in each category.

\section{The Survey}

The survey was based on Grounded Theory and Social Cognitive Career Theory ${ }^{9}$ in working with these students, this class, and the 4.0 Plan for many years. The survey included 24 activities associated with the Guaranteed 4.0 Plan. The students were asked to rate each item as Very Important, Important, Neutral, Not Important, or Not at All Important. For analysis, 5 points were assigned to Very Important, 4 points to Important, on down to 1 point for Not at All Important. The students were then asked which activities of the 24 they would rank as the most important to them in order to a top pick, a second pick, and a third pick. 
The students were also asked if they believe that their GPA is higher now than it would have been if they had not adopted parts of the 4.0 Plan. Students with a 4.0 GPA before they knew about the Plan were asked if the Plan had made it any easier for them to maintain their good grades. Lastly, the students were asked if they do any activities other than the 24 listed in the survey to help them learn the material in their classes and help them to do well in their classes. If a student answered "yes," they were asked to identify these activities.

\section{The Survey Results}

First we looked at the average ranking of the 24 items listed as activities associated with the 4.0 Plan. These results are given in Table II below. The students ranked the items from Very Important (5) to Not at All Important (1). The average rankings ranged from 3.64 which is tending to Important to 4.58 which between Important and Very Important. All of the item averages were within one point.

Table II. Average rankings of Importance of Academic Success and Professional Development Class Activities Related to the 4.0 Plan: 5=Very Important; 4=Important; 3=Neutral; 2=Not Important; 1=Not at all Important

\begin{tabular}{|l|l|l|}
\hline 4.0 RELATED ACTIVITY & AVERAGE RANK & OVERALL RANK \\
\hline Graduate school & 4.58 & 1 \\
\hline Start assignment day it is assigned & 4.47 & 2 \\
\hline Career Planning & 4.45 & 3 \\
\hline Know how to catch up without getting behind & 4.43 & 4 \\
\hline Get 8 hours of sleep & 4.37 & 5 \\
\hline Be in study group for each (or most) class & 4.34 & 6 \\
\hline The actual METS Center to meet and study & 4.28 & 7 \\
\hline Sit front \& center in class & 4.26 & 8 \\
\hline Class Encouragement & 4.20 & 9 \\
\hline Bullet Point Concepts (go over HW and exams) & 4.18 & 10 \\
\hline Get to know each professor & 4.14 & 11.5 \\
\hline Seeing graduate school models & 4.14 & 11.5 \\
\hline Involved in research & 4.125 & 13 \\
\hline Involved in student organizations & 4.09 & 14 \\
\hline Improving habits to reduce stress (Carlson) & 4.07 & 15 \\
\hline Go to POH (Professor Office Hours) & 4.07 & 16 \\
\hline Detailed Time Management Schedule & 4.05 & 17 \\
\hline Read texts before class, but no Bullet Points & 4.04 & 18 \\
\hline Bullet Point Notes & 3.80 & 19 \\
\hline Bullet Point Reading for classes with texts & 3.79 & 20 \\
\hline Practice SLANT & 3.70 & 21 \\
\hline Interest Paper & 3.67 & 22 \\
\hline Stop after 20 minutes if stuck & 3.66 & 23 \\
\hline Being told to do what I need to do & 3.64 & 24 \\
\hline
\end{tabular}


Next the top three activities of importance to the student were considered. Table III, column 3 shows the number of times an activity was mentioned in the top three by the students. Column 4 shows the top three rank total where an activity was given a 3 is it was a first choice, a 2 if it was a second choice, and a 1 if it was a third choice. The overall ranks shown in Table II are shown in column 2 for comparison.

Table III. Top 3 Activities of Academic Success and Professional Development related to the 4.0 Plan: Number of times in Top 3; Top 3 by rank: 3=\#1 rank, 2=\#2 rank, and 1=\#3 rank.

\begin{tabular}{|l|l|l|l|}
\hline 4.0 RELATED ACTIVITY & $\begin{array}{l}\text { AVERAGE } \\
\text { RANK }\end{array}$ & \# TIMES TOP 3 & $\begin{array}{l}\text { TOP 3 RANK } \\
\text { TOTAL }\end{array}$ \\
\hline Get 8 hours of sleep & 4.37 & 23 & 56 \\
\hline Start assignment day it is assigned & 4.47 & 17 & 32 \\
\hline Graduate school & 4.58 & 16 & 26 \\
\hline Detailed Time Management Schedule & 4.05 & 15 & 33 \\
\hline Career Planning & 4.45 & 13 & 23 \\
\hline Be in study group for each (or most) class & 4.34 & 12 & 25 \\
\hline Involved in research & 4.125 & 11 & 22 \\
\hline Go to POH (Professor Office Hours) & 4.07 & 10 & 20 \\
\hline Sit front \& center in class & 4.26 & 9 & 17 \\
\hline Bullet Point Notes & 3.80 & 9 & 19 \\
\hline Involved in student organizations & 4.09 & 7 & 10 \\
\hline Read texts before class, but no Bullet Points & 4.04 & 4 & 10 \\
\hline Know how to catch up without getting behind & 4.43 & 6 \\
\hline Bullet Point Reading for classes with texts & 3.79 & 3 & 7 \\
\hline Bullet Point Concepts (go over HW and exams) & 4.18 & 2 & 2 \\
\hline Get to know each professor & 4.14 & 2 & 4 \\
\hline Seeing graduate school models & 4.14 & 2 & 6 \\
\hline Improving habits to reduce stress (Carlson) & 4.07 & 2 & 2 \\
\hline The actual METS Center to meet and study & 4.28 & 1 & 3 \\
\hline Class Encouragement & 4.20 & 1 & 1 \\
\hline Interest Paper & 3.67 & 1 & 3 \\
\hline Stop after 20 minutes if stuck & 3.66 & 1 & 2 \\
\hline Practice SLANT & 3.70 & 0 & 0 \\
\hline Being told to do what I need to do & 3.64 & 0 & \\
\hline
\end{tabular}

\section{/}

The students were asked what their GPA was currently and what it was before they knew about the 4.0 Plan. Of these self-reported scores, 16 students showed an improved GPA, 13 showed no change ( 5 of these maintained a 4.0) and 4 students showed a decline in GPA. The declines were $.03, .09, .30$, and .63. Students who were learning about the 4.0 Plan for the first semester were not included in these results and not all students reported their grades.

Next the students were asked if they believed that their GPA was higher now than it would have been if they had not adopted parts of the 4.0 Plan. First semester transfers and students new to the 4.0 Plan were not included in the results. To this question, 35 students said "Yes" and 8 
students said "No." Of these 8 students, three had a 4.0, four had increased their GPA since learning about the 4.0 Plan, and one student did have a decline in their GPA from 3.8 to 3.71 . Students with a 4.0 before they learned about the 4.0 Plan were asked if the 4.0 Plan made getting a 4.0 any easier. Five of the seven students said "Yes."

Lastly, the students were asked if they did activities other than the ones listed in the survey which help them learn material in their class and help them do well in their classes. Seventeen of the students said "Yes." Table IV shows their additional activities.

Table IV. Additional Activities used by Students to Learn Material (17 students, some with more than one activity)

\begin{tabular}{|l|l|l|}
\hline NUMBER & ADDITIONAL ACTIVITY TO HELP LEARN MATERIAL & $\begin{array}{l}\text { NUMBER OF } \\
\text { STUDENTS }\end{array}$ \\
\hline 1. & $\begin{array}{l}\text { Additional Self Study } \\
\text { Research material beyond class } \\
\text { On-line videos/YouTube } \\
\text { Use the tutoring center }\end{array}$ & 5 \\
\hline 2. & Do lots of practice problems from the text & 4 \\
\hline 3. & Finish assignments a few days before they are due & 1 \\
\hline 4. & Talk about concepts with study group & 1 \\
\hline 5. & Study sessions with other students & 1 \\
\hline 6. & Outlet for stress & 1 \\
\hline 7. & Create constantly updated to do list & 1 \\
\hline 8. & Work on personal projects outside of school & 1 \\
\hline 9. & Internship & 1 \\
\hline 10. & Be flexible & 1 \\
\hline 11. & & \\
\hline
\end{tabular}

Several of these activities are closely related to 4.0 Plan principles.

\section{Discussion of Survey Results}

Table I shows that the average ranks of the 24 items are all between 3.64 and 4.58, indicating that the students on average take all of the items seriously. Some of the items are strictly from the Guaranteed 4.0 Learning System and others are complementing items that are stressed in the Academic Success and Professional Development course. It was somewhat surprising to see that the item with the highest rank average was "graduate school." The advantages of graduate school are stressed in the class. The students in this class are told that, if possible, it is best that when a student graduates, she/he go right on to graduate school full-time. Reasons for this encouragement include the fact that it is much easier to concentrate on graduate school full-time than taking courses above a 40-50 hour work week. Even if the company is paying for the graduate classes, it is very difficult to take 2 or more graduate courses while working. If a student only takes one course per semester while working, it may take five years and the student may have changed jobs by that time. A major reason for students to go to graduate school is that they are more likely to secure a challenging, interesting career. ${ }^{4,5,6} \mathrm{~A}$ nice side benefit of a graduate degree is that the starting salary is usually $\$ 10-15 \mathrm{~K}$ higher. The students in the Academic Success Class are encouraged to join a 4+1 program at ASU in which 2-3 classes can 
be taken for double credit, both undergraduate and graduate credit. This enables the students to earn a Master's degree in engineering or computer science in one academic year after they graduate. The GPA minimum for the program ranges from 3.2-3.5, depending on the major. During the Academic Success Class, graduate students put on a "The Nuts and Bolts of Graduate School" to help the students. In addition, a Graduate Student Panel presents for one meeting in which the graduate students tell it like it really is. This meeting is usually the favorite of the year and gives all of the students strong encouragement to go on to graduate school. Since the program has a focus on females, underrepresented minority, and transfer students, we particularly urge them to get a graduate degree, to be able to move up in their profession, and to become a leader. The graduated scholarship students in the program have been going right on to graduate school at a $50 \%$ rate. The program appears to be the difference since less than $20 \%$ of newly graduated engineers go right on to graduate school nationally, and only about $11 \%$ of upper division transfer ENGR students at ASU usually go directly to graduate school. The 4.0 Plan does not per se advocate graduate school, however, all of the 4.0 activities help a student improve his/her grade point to make it possible. Internships and research positions are encouraged in this program for students to gain some experience along the way before they complete their graduate degree.

The second highest rank belongs to "Start assignment the day it is assigned." This activity is straight from the Guaranteed 4.0 Plan. Students need to be reminded to do this. With an early start the student can estimate how long the assignment will take and have time to schedule extra time in their detailed time management chart, have time to meet with their study group, and also time to consult with their professor, if needed. It is good to know that the students recognize and consider this very important.

Career Planning, in third place, is another activity that is unique to the Academic Success class, in addition to the 4.0 Plan. In the spring semester, the students are asked to plan out their career for 10 years beyond their bachelor's degree. There are over 20 categories that they need to plan, all the way from where they will live, to how many children, to what type of savings plan they will use. The students are also encouraged to have a Plan B in case the top choice does not work out. This assignment has been described by students as their most creative of any of their assignments to a very difficult task. Obviously as the students look at the plan each year they may be surprised to learn that they are exactly on their same plan, while others may see that they now need to make several major revisions

The next three items, catching up, 8 hours of sleep, and study groups are strictly out of the 4.0 Plan. The high ranking of the "catching up activity" is surprising. Another surprise is that the Bullet Point Reading is ranked $20^{\text {th }}$ out of 24 . Even reading the text without bullet points is only ranked $18^{\text {th }}$. For some seniors, only a few of their courses have textbooks, which may have influenced this ranking. Bullet Point Concepts, going over homework and exams ranked $10^{\text {th }}$. Stopping after 20 minutes is the only real 4.0 Plan item in that last four ranks. SLANT stands for Sit front and center, Lean forward, Accurate notes, Nod (show approval or lack of understanding), and Track the speaker. The interest paper ranked at 22 is very difficult for some students. The purpose of the assignment is to get the student involved in research. A "research" 
paper was changed to an "interest" paper to make the assignment less daunting. Although several students have testified that the reason they continue to come semester after semester to the Academic Success class is that they need to be told to keep doing the right thing, this item received the lowest ranking. However, the ranking of 3.64 would indicate the item was considered on average more "important" than "neutral."

The fundamental word in Table I was how important the student thought a particular activity. Next the students were asked to identify the top three items of importance to them. There was some correlation between the two result and some differences. Five of the items in the top 6 are the same in each table. The "know how to catch up" which ranked fourth in importance on Table I only ranked $13^{\text {th }}$ in personal importance. On the other hand, the detailed time management was ranked fourth by importance to the student, where it was ranked $17^{\text {th }}$ out of 24 on importance. Overwhelmingly, getting 8 hours of sleep was the most popular top rank in importance to the students. In personal importance, getting involved in research ranked $6^{\text {th }}$, while it ranked $13^{\text {th }}$ in general importance.

Of particular interest, also, is what other activities students used that they thought were useful to them being a successful student as shown on Table III. The most often named item (by 5 students) said that they used on-line videos and instruction. It is possible that other students also use this method, but did not think to note it on the survey. Using the tutoring center is strongly encouraged in class. Doing lots of practice problems is also something that more students may be doing. Finishing the assignments a few days before they are due is almost certainly a corollary to starting homework when it is assigned. Hopefully talking about concepts in their study group is something that most students do. The fact that it is mentioned as an additional activity means, perhaps, that it should be pointed out that study groups are good for more than just checking answers. The usefulness of a "to do" list for small items such as Grandma's birthday card, which normally would not regularly go on the detailed time management schedule, is discussed in class. Having an outlet for stress is certainly part of the 4.0 Plan and emphasized by Johnson. Learning to be flexible can lower stress and make it easier to learn material.

\section{Conclusions}

The results of this survey were, in general, reassuring that the students are taking the Guaranteed 4.0 Plan seriously. The low rank (17/24) for the importance of the detailed time management schedule was somewhat surprising, but it was ranked fourth when students selected the top three activities that were important to them. For the schedule to be fourth after 8 hours of sleep, starting assignments right away, and graduate school, is not trivial. It is also somewhat of a surprise that students did not rank bullet point reading higher, although this is not necessarily a measure of how much they actually bullet point. Certainly, among good students, it has been noted that they consider different aspects of the 4.0 Plan to be the most important. As a followon it would be interesting to compare the student GPAs with the 4.0 Plan activities they consider most important. A discussion on this survey with the students and how they chose their rankings could shed additional light on the results of this survey. 


\section{References}

1. Johnson, D.O. and Chen, Y. C. (2004). “Guaranteed 4.0 Plan,” JCYC Studio, Dallas, Texas.

2. Anderson-Rowland, M.R., Rodriguez, A.A., (2015) "The Evolution of a Collaborative Interdisciplinary Research Community," 2015 American Society for Engineering Education Annual Conference and Exposition, Conference Proceedings, Seattle, WA, 11 pages.

3. Anderson-Rowland, M.R., Rodriguez, A.A., and Grierson, A.E., (2015) "METSTEP after Six Years," 2015 American Society for Engineering Education Annual Conference and Exposition, Conference Proceedings, Seattle, WA, 7 pages.

4. Anderson-Rowland, M.R. and Johnson, P.C. (2004). "Encouraging Underrepresented Minority and Women Students to Become Interested in Research and to Attain Graduate Degrees," ASEE Annual Conference and Exposition, Conference Proceedings.

5. Anderson-Rowland, M.R., Buckingham, P.A., and Zerby, D.L. (2005). "Increasing the Number of Minority and Women Students Obtaining a Graduate Degree," Proceedings of the 2005 WEPAN-NAMEPA Joint Conference.

6. Anderson-Rowland, M.R. (2008). "Thinking about Graduate School,” ASEE Annual Conference and Exposition, Conference Proceedings.

7. Anderson-Rowland, M.R. \& Rowland, J.R. (2007). "The Correlation between GPA and Percent Effort on the Guaranteed 4.0 Plan," 37th ASEE/IEEE Frontiers in Education Conference. 2007. http://fie.engrng.pitt.edu/fie2007/index.html

8. Anderson-Rowland, M.R. (2011). "Reducing GPA shock for Engineering and Computer Science Community College Transfer Students," American Society for Engineering Education Annual Conference and Exposition, Conference Proceedings. 2011.

9. Lent, R.W., Brown, S.D., and Hackett, G. (1994). "Towards a Unifying Social Cognitive Theory of Career and Academic Interest, Choice, and Performance," Journal of Vocational Behavior, Vol. 45, No 1, 1994, pp.79-122. 